\title{
PENGEMBANGAN MODUL PEMBELAJARAN IPS MATERI KEGIATAN EKONOMI BERMUATAN NILAI KARAKTER UNTUK SISWA KELAS IV SEKOLAH DASAR
}

\author{
Siti Nurjanah $^{1}$, Tin Rustini ${ }^{2}$, Asep Rudi Nurjaman ${ }^{3}$ \\ sitinurjanah@upi.edu',tinrustini@yahoo.com², asrun85mubarrok@gmail.com³ \\ Pendidikan Guru Sekolah Dasar, Universitas Pendidikan Indonesia Kampus Cibiru
}

\begin{abstract}
This research is based on the need for attractively packaged teaching materials to be used by fourth grade elementary school students as a supporter of the learning process so as to create independent learning. Based on this, the purpose of this study is to describe and develop a product, namely a learning module that is suitable for use. The research method used is the D\&D (Design and Development) research method using the ADDIE research procedure (Analyze, Design, Development, Implementation, and Evaluation). For the validation of this Social Studies learning module, it involves experts consisting of material experts, linguists, and media experts as well as assessments from teachers and students. The results of product assessment by material experts get a value of $97.36 \%$ in the "very feasible" category, the results of product assessment by linguists get a value of $91.66 \%$ in the "very feasible" category, and the results of product assessment by media experts get a value of $95.58 \%$ with the category "very decent". In a limited field trial conducted at SDN Pangsor, the results of the product assessment by students got a score of $99 \%$ in the "very feasible" category and the results of the product assessment by the teacher got a score of $95 \%$ in the "very decent" category. Therefore, the social studies learning module that has been developed by this researcher is very suitable for use for fourth grade elementary school students in supporting the learning process.
\end{abstract}

\begin{abstract}
ABSTRAK
Penelitian ini didasarkan atas perlunya bahan ajar yang dikemas secara menarik untuk digunakan oleh siswa kelas IV sekolah dasar sebagai penunjang proses pembelajaran sehingga mampu menciptakan kemandirian belajar. Berdasarkan hal tersebut, tujuan penelitian ini adalah untuk mendeskripsikan dan mengembangkan suatu produk yaitu modul pembelajaran yang layak digunakan. Metode penelitian yang digunakan yaitu metode penelitian D\&D (Design and Development) dengan menggunakan prosedur penelitian ADDIE (Analyze, Design, Development, Implementation, and Evaluation). Untuk validasi modul pembelajaran IPS ini melibatkan para ahli yang terdiri dari ahli materi, ahli bahasa, dan ahli media serta penilaian dari guru dan siswa. Hasil penilaian produk oleh ahli materi mendapatkan nilai 97,36\% dengan kategori "sangat layak", hasil penilaian produk oleh ahli bahasa mendapatkan nilai $91,66 \%$ dengan kategori "sangat layak", dan hasil penilaian produk oleh ahli media mendapatkan nilai 95,58\% dengan kategori "sangat layak". Pada uji coba lapangan terbatas yang dilakukan di SDN Pangsor, hasil penilaian produk oleh siswa mendapatkan nilai 99\% dengan kategori "sangat layak" dan hasil penilaian produk oleh guru mendapatkan nilai $95 \%$ dengan kategori "sangat layak". Maka dari itu, modul pembelajaran IPS yang telah dikembangkan oleh peneliti ini sangat layak digunakan untuk siswa kelas IV sekolah dasar dalam menunjang proses pembelajaran.
\end{abstract}

Kata Kunci : Penelitian D\&D, Pengembangan Modul Pembelajaran, Pembelajaran 


\section{PENDAHULUAN}

Proses pendidikan erat kaitannya dengan proses kegiatan belajar dan pembelajaran. Kegiatan belajar dan pembelajaran merupakan dua hal yang tidak dapat terpisahkan satu sama lain sehingga memiliki keterkaitan yang erat. Dalam suatu kegiatan pembelajaran tentunya ada pelaku, yaitu guru dan peserta didik. ${ }^{1}$ Proses pendidikan diatur dalam UndangUndang No. 20 Tahun 2003 tentang Sistem Pendidikan Nasional.

Menurut Susanto mengemukakan bahwa mata pelajaran IPS (Ilmu Pengetahuan Sosial) adalah suatu ilmu yang mengkaji berbagai disiplin-disiplin ilmu sosial, ilmu humaniora serta kegiatan dasar yang dilakukan oleh manusia yang dikemas secara ilmiah dalam rangka memberi wawasan dan pemahaman yang mendalam kepada peserta didik, khususnya di tingkat dasar dan menengah. Melalui mata pelajaran IPS, hal-hal yang diajarkan meliputi ranah pengetahuan, sikap, dan keterampilan yang dikembangkan secara holistik agar peserta didik dapat menjadi warga negara yang demokratis, bertanggung jawab, serta menjadi warga negara yang baik sesuai cita-cita bangsa. ${ }^{2}$ Implementasi pembelajaran IPS melibatkan nilai-nilai yang terdapat di masyarakat. Oleh karena itu, nilai-nilai karakter dapat dikembangkan melalui pembelajaran IPS. Adanya pengembangan nilai-nilai budaya dan karakter dalam proses pembelajaran di sekolah bertujuan agar peserta didik dapat mengimplementasikannya di kehidupan sehari-hari sebagai pribadi, anggota keluarga, masyarakat, dan warga negara yang memiliki karakter yang baik diantaranya religius, nasionalis, produktif, kreatif, dan inovatif. ${ }^{3}$

Saat ini telah memasuki abad 21. Pendidikan nasional meletakkan pendidikan karakter sebagai jiwa utama dalam implementasi pendidikan bagi peserta didik sebagai langkah utama untuk menghadapi tantangan abad 21. Pembelajaran IPS memiliki peranan yang sangat strategis dalam membentuk karakter peserta didik. Pendidikan karakter dan pembelajaran IPS memiliki arah dan tujuan yang sama, yakni menciptakan peserta didik agar menjadi warga negara yang baik. Dalam pembelajaran IPS perlunya pengarahan terhadap pengembangan pendidikan karakter dalam membangun kecerdasan, akhlak, dan kepribadian peserta didik sehingga relevan dengan tujuan pendidikan bangsa. ${ }^{4}$ Oleh karena itu, internalisasi nilai-nilai karakter dapat dilakukan dalam pendidikan.

Dalam proses pembelajaran terdapat komponen-komponen pembelajaran meliputi tujuan pendidikan, peserta didik, pendidik, bahan atau materi pelajaran, pendekatan atau

\footnotetext{
${ }^{1}$ Dimyati \& Mudjiono, Belajar dan Pembelajaran, Jakarta: Rineka Cipta, 2015.

2 Madona \& Yulfia, Pengembangan IPS Berbasis Multimedia Interaktif untuk Siswa SD Kelas IV Sekolah Dasar, Jurnal Pelangi, No. 2 Vol. 8, Th. 2016, h. 221-228.

${ }^{3}$ Rustini, T, Pendidikan Karakter Anak Usia Dini, Jurnal Pendidikan Anak Usia Dini, No. 1 Vol. 3. Th. 2012.

${ }^{4}$ Marhayani, D, Pembentukan Karakter melalui Pembelajaran IPS, Jurnal Edunomic, No. 2 Vol. 5, Th. 2017, h. 67-75.
} 
metode, media atau alat, sumber belajar dan evaluasi. ${ }^{5}$ Merujuk pada komponen tersebut, bahan ajar atau materi dianggap sebagai salah satu aspek yang paling krusial dalam keberlangungan pembelajaran. Keberhasilan belajar peserta didik sangat dipengaruhi oleh pemilihan bahan ajar yang disesuaikan dengan kebutuhan peserta didik itu sendiri. ${ }^{6} \mathrm{Hal}$ tersebut sejalan dengan pendapat. ${ }^{7}$ yang menyatakan bahwa dalam penyusunan bahan ajar memiliki tujuan yang relevan dengan tuntutan kurikulum yang berlaku dan tentunya harus memperhatikan kebutuhan peserta didik.

Dalam pelaksanaan pembelajaran, tidak jarang guru dan peserta didik mengalami keterbatasan sumber belajar. Hal ini dijelaskan oleh hasil penelitian Krissandi dan Rusmawan. ${ }^{8}$ yang menemukan bahwa salah satu kendala guru sekolah dasar dalam implementasi Kurikulum 2013 adalah kendala dari ketersediaan dan kekurangan-kekurangan buku dari pemerintah. Selain itu, ditemukannya kesadaran peserta didik akan hal belajar mandiri masih rendah dan peserta didik hanya menggunakan LKS saja sebagai sumber belajarnya. Maka dari itu, guru dan peserta didik memerlukan bahan ajar penunjang.

Solusi dari permasalahan ini yaitu memberikan suatu bahan ajar yang dapat dipelajari oleh peserta didik secara mandiri yaitu berupa modul pembelajaran. Terkait dengan pengembangan bahan ajar, saat ini pengembangan bahan ajar dalam bentuk modul dapat memberikan kontribusi yang besar karena dapat mewujudkan pembelajaran yang berkualitas serta kegiatan pembelajaran lebih terencana secara mandiri, tuntas sehingga menghasilkan output yang jelas. ${ }^{9}$

Modul yang dikembangkan yaitu modul pembelajaran IPS yang bermuatan nilai-nilai karakter. Modul pembelajaran yang dikembangkan dapat dikemas dengan cara mengintegrasikan pembelajaran dengan nilai-nilai karakter. ${ }^{10}$ Nilai-nilai karakter dapat dintegrasikan ke dalam mata pelajaran tanpa mengubah materi pelajaran yang telah termuat

${ }^{5}$ Dolong, H, Teknis Analisis dalam Komponen Pembelajaran, UIN Syarif Hidayatullah, Jakarta, No. 2 Vol. 5, Th. 2016, h. 293-300.

${ }^{6}$ Wati, dkk, Analisis Kebutuhan Terhadap Bahan Ajar Game Based Learning Terintegrasi Karakter Kreatif. Jurnal Pendidikan Karakter, No. 2 Vol. 10, Th. 2020, h. 182-183.

${ }^{7}$ Daryanto, Pembelajaran Tematik, Terpadu, Terintegrasi (Kurikulum 2013), Yogyakarta: Gava Media, 2014.

8 Susilawati, dkk, Pentingnya Pengembangan Bahan Ajar Tematik Dalam Meningkatkan Karakter Peduli Lingkungan Siswa. Jurnal Pendidikan Dasar, No. 1 Vol. 12, Th. 2020, h. 62-68.

${ }^{9}$ Wahyuningtyas, Penggunaan Modul Pembelajaran Penjumlahan dan Pengurangan Bilangan Bulat dengan Pendekatan CTL (Contextual Teaching and Learning) Untuk Meningkatkan Pemahaman Konsep Siswa Kelas IV Sekolah Dasar, Jurnal Pendidikan, No. 1 Vol. 2, Th. 2017, h. 8-9.

10 Estuwardani \& Ali, Pengembangan Bahan Ajar Modul Tematik-Integratif dalam Peningkatan Karakter Peserta Didik Kelas 1 Sekolah Dasar, Jurnal Pendidikan Karakter, No. 2 Vol. 5, Th. 2015, h. 157-172. 
dalam kurikulum. ${ }^{11}$ Modul yang dikembangkan diharapkan dapat membantu peserta didik dalam menciptakan kemandirian belajar.

\section{METODOLOGI PENELITIAN}

Dalam penelitian ini, metode penelitian yang digunakan ialah penelitian pengembangan. Adapun jenis penelitian pengembangan yang digunakan ialah Design and Development (D\&D). Richey \& Klein (2007) menjelaskan bahwa Design and Development sebagai metode penelitian yang sistematis mengenai desain, pengembangan dan proses evaluasi yang berkaitan dengan produk dan perangkat instruksional maupun non instruksional yang baru maupun pengembangan yang sudah ada.

Prosedur penelitian D\&D sangat bervariasi dari berbagai pendapat ahli. Adapun dalam penelitian ini menggunakan model ADDIE. ${ }^{12}$ Model ADDIE terdiri dari lima tahapan yaitu analyze (analisis), design (perancangan), development (pengembangan), implementation (implementasi), dan evaluation (evaluasi).

Penelitian ini dilakukan di SDN Pangsor, Cimanggung, Sumedang sebanyak 10 peserta didik. Instrumen penelitian ini yaitu wawancara dan angket. Wawancara dilakukan kepada guru kelas IV sedangkan angket validasi digunakan untuk validasi produk oleh para ahli (ahli materi, ahli bahasa, dan ahli media) dan angket respon terhadap produk oleh peserta didik dan guru. Jenis data yang diperoleh dari uji coba produk pengembangan modul materi kegiatan ekonomi bermuatan nilai karakter ini terdiri dari dua jenis, yaitu data kuantitatif yang diperoleh dari instrumen pengumpulan data dan data kualitatif dari saran dan komentar perbaikan produk yang diperoleh dari para ahli, peserta didik, dan guru. Adapun analisis data yang digunakan menggunakan rumus sebagai berikut:

$$
\mathrm{Ps}=\frac{S}{n} \times 100 \%
$$

$$
\begin{aligned}
& \text { Ps }=\text { Persentase } \\
& \mathrm{S}=\text { Jumlah skor yang didapat } \\
& \mathrm{N}=\text { Jumlah skor ideal }
\end{aligned}
$$

\section{HASIL PENELITIAN DAN PEMBAHASAN}

Dalam rancangan modul pembelajaran IPS materi kegiatan ekonomi bermuatan nilai karakter ini, peneliti melakukan 5 tahapan dengan merujuk pada model ADDIE.

\footnotetext{
${ }^{11}$ Ernalis, Syahruddin \& Abidin, Pengembangan Model Bahan Ajar Bahasa Indonesia Berbasis Model Pembelajaran yang Berorientasi pada Pendidikan Karakter, Jurnal Pendidikan Dasar, No. 1 Vol. 5, Th. 2016, h. $1-10$.

${ }^{12}$ Jampel, Tegeh \& Pudjawan, Model Penelitian Pengembangan, Yogyakarta: Graha Ilmu, 2014.
} 


\section{Tahap Analyze (Analisis)}

Pada tahap analisis dalam penelitian ini, terdapat tiga aspek yang dianalisis yaitu kompetensi dasar, karakteristik peserta didik, dan materi. Pada tahap analisis kompetensi dasar, peneliti merujuk pada Permendikbud No. 37 Tahun 2018 tentang Kompetensi Inti dan Kompetensi Dasar. Adapun kompetensi dasar yang diambil untuk mengembangkan modul ini yaitu 3.3 dan 4.3 dalam mata pelajaran IPS untuk kelas IV SD. Kompetensi dasar yang dimaksud yaitu 3.3 Mengidentifikasi kegiatan ekonomi dan hubungannya dengan berbagai bidang pekerjaan serta kehidupan sosial dan budaya di lingkungan sekitar sampai provinsi dan 4.3 Menyajikan hasil identifikasi kegiatan ekonomi dan hubungannya dengan berbagai bidang pekerjaan, serta kehidupan sosial dan budaya di lingkungan sekitar sampai provinsi. Tahap analisis karakteristik peserta didik, peneliti melakukan wawancara kepada Guru kelas IV SDN Pangsor. Hasil wawancara terkait karakteristik peserta didik yaitu peserta didik kelas IV menyukai bahan ajar yang dikemas secara menarik, berwarna, dan terdapat gambar/ilustrasi yang relevan dengan kehidupan sehari-hari. Hal ini sejalan dengan pendapat Septianti \& Rara yang mengungkapkan bahwa dalam menyampaikan materi pelajaran guru harus mengetahui karakteristik peserta didik sehingga dapat dijadikan pijakan dalam pembelajaran agar peserta didik mampu mengikuti dan memahami pelajaran dengan baik. ${ }^{13}$ Selain modul tersebut disesuaikan dengan karakteristik peserta didik, tentunya modul juga harus disesuaikan dengan materi pembelajaran. ${ }^{14}$ Tahap analisis materi, peneliti melakukan analisis dengan cara menentukan materi yang dikembangkan. Pemilihan materi kegiatan ekonomi ini karena proses kegiatan ekonomi sering dilakukan dalam kehidupan sehari-hari. Oleh karena itu, perlunya ditanamkan juga terkait nilai karakter dalam melakukan kegiatan ekonomi agar proses tersebut berjalan dengan baik. Dalam melakukan tahap analisis tersebut, peneliti melihat sumber-sumber referensi yang sesuai dengan materi yang dikembangkan.

2. Tahap Design (Perancangan)

Pada tahap perancangan dalam penelitian ini, peneliti menyusun isi modul berdasarkan kompetensi dasar, melakukan penyusunan materi, kemudian menentukan bentuk evaluasi. Materi yang dikembangkan mengenai Kegiatan Ekonomi yang terintegrasi dengan nilai-nilai karakter yaitu jujur, mandiri, peduli sosial, disiplin, religius, toleransi, kerja keras, peduli lingkungan, bersahabat/komunikatif, tanggung jawab, kreatif, dan rasa ingin tahu. Peneliti melakukan studi pustaka untuk mencari berbagai referensi. Selain itu, peneliti mempersiapkan alat dan bahan untuk membuat modul yaitu Microsoft Word dan Website Canva.

\footnotetext{
${ }^{13}$ Septianti \& Rara, Pentingnya Memahami Karakteristik Siswa Sekolah Dasar di SDN Cikokol 2, Jurnal Pendidikan Islam Anak Usia Dini, No. 1 Vol. 2, Th. 2020, h. 7-17.

${ }^{14}$ Arlyanti, Kosasih, \& Apriliya, Pemilihan Bahan Ajar Cerita Anak Berdasarkan Karakteristik Siswa $S D$, Pedadikta: Jurnal Ilmiah Pendidikan Guru Sekolah Dasar, No. 1 Vol. 5 Th. 2018, h. 221-231.
} 


\section{Tahap Development (Pengembangan)}

Pada tahap pengembangan, peneliti menjelaskan pengembangan produk dari awal penentuan ukuran dan format modul, penentuan unsur-unsur modul, penggunaan bahasa, membuat desain hingga pembuatan hardcopy.

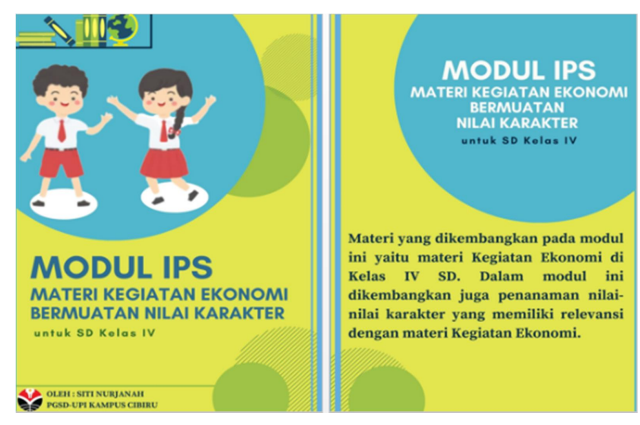

Gambar 1. Tampilan Cover

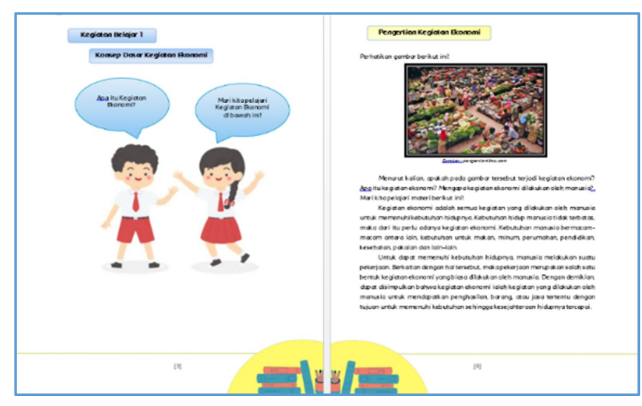

Gambar 2. Tampilan Isi Modul

Setelah modul selesai diproduksi, selanjutnya modul divalidasi oleh para ahli untuk mengetahui kelayakan modul ditinjau dari aspek materi, aspek kebahasaan, aspek kegrafikan, dan aspek penyajian yang merujuk kepada BSNP. ${ }^{15}$ Berikut data yang diperoleh dari hasil validasi oleh para ahli.

Tabel 1. Rekapitulasi Hasil Kelayakan

\begin{tabular}{|c|c|c|}
\hline No & Aspek & Skor \\
\hline 1 & Ahli Materi & $97,36 \%$ \\
\hline 2 & Ahli Bahasa & $91,66 \%$ \\
\hline 3 & Ahli Media & $95,58 \%$ \\
\hline
\end{tabular}

Berdasarkan hasil penilaian uji kelayakan modul, dari ahli materi mendapatkan persentase $97,36 \%$ modul yang dikembangkan sangat layak digunakan dalam proses

${ }^{15}$ Purwono, Urip, Standar Penilaian Bahan Ajar, Jakarta: BSNP, 2008. 
pembelajaran. Saran dari ahli materi yaitu penambahan materi seperti pemberian contoh pekerjaan di era sekarang/corak kehidupan modern, kegiatan ekonomi di bidang kuliner, distribusi online, dan penambahan bacaan terkait nilai karakter toleransi. Berdasarkan hasil penilaian uji ahli bahasa mendapatkan persentase $91,66 \%$ modul yang dikembangkan sangat layak digunakan dalam proses pembelajaran. Tidak ada saran dari ahli bahasa. Selanjutnya, hasil penilaian uji ahli media mendapatkan persentase $95,58 \%$ modul yang dikembangkan sangat layak digunakan dalam proses pembelajaran. Saran dari ahli media yaitu dalam penyajian materi lebih komunikatif sehingga menunjukkan komunikasi antar penulis dengan pembaca kemudian di bagian latihan perlu diberikan petunjuk yang jelas dengan memberikan rambu-rambu untuk menjawabnya. Dengan adanya saran dan masukan tersebut menjadi pedoman bagi peneliti untuk memperbaiki modul sehingga produk yang dihasilkan dapat lebih maksimal.

\section{Tahap Implementation (Implementasi)}

Modul yang telah dikembangkan oleh peneliti kemudian diuji coba kepada peserta didik kelas IV SDN Pangsor. Uji coba dilakukan pada hari Sabtu, 31 Juli 2021. Di masa pandemi seperti sekarang ini, peserta uji coba dilakukan secara terbatas. Peserta uji coba modul ini berjumlah 10 orang yang terdiri dari 3 orang laki-laki dan 7 orang perempuan. Selain respon dari peserta didik, peneliti juga memerlukan respon dari guru.

Tabel 2. Rekapitulasi Respon

\begin{tabular}{|c|c|c|}
\hline No & Aspek & Skor \\
\hline 1 & Aspek Peserta didik & $99 \%$ \\
\hline 2 & Aspek Guru & $95 \%$ \\
\hline
\end{tabular}

Berdasarkan hasil respon dari peserta didik terhadap modul, peserta didik sangat menyukai tampilan dan isi modul baik dari segi warna, gambar serta tulisan yang tidak terlalu kecil dan tidak terlalu besar. Hal tersebut selaras dengan pendapat Stewig bahwa dalam pengembangan buku untuk peserta didik, informasi yang dipaparkan diperkuat dengan warna-warna dalam gambar. ${ }^{16}$ mengemukakan penggunaan warna-warna dalam buku materi pelajaran yaitu menambah atau mendekati fakta yang sebenarnya, membedakan dan menghubungkan antar elemen serta menarik perhatian. Adapun respon dari guru, modul mudah digunakan. Sejalan dengan yang disampaikan oleh Sukiman bahwa salah satu syarat pengembangan modul yaitu memenuhi kaidah user friendly atau praktis dan mudah digunakan oleh peserta didik.

${ }^{16}$ Stewig, J.W, Children's Preference in Picture Book Illustration, Education Leadership Journal, No. 2 Vol 3, Th. 2013, h. 273-279. 


\section{Tahap Evaluation (Evaluasi)}

Pemaparan evaluasi berdasarkan evaluasi berupa saran dan masukan dari para ahli yang terlibat dalam melakukan validasi modul pembelajaran ini. Menurut ahli materi disarankan agar menambahkan materi seperti pemberian contoh pekerjaan di era sekarang/corak kehidupan modern, penjelasan mengenai kegiatan ekonomi di bidang kuliner, penjelasan distribusi online, dan penambahan bacaan terkait nilai karakter toleransi. Menurut ahli bahasa, tidak ada revisi dari segi kebahasaan karena sudah sesuai dengan karakteristik siswa kelas IV SD. Adapun menurut ahli media, disarankan agar penyajian materi lebih komunikatif serta pada bagian latihan diberikan petunjuk yang jelas dengan memberikan rambu-rambu agar peserta didik dapat menjawab.

\section{KESIMPULAN}

Modul pembelajaran IPS bermuatan nilai karakter ini merupakan produk yang dikembangkan berdasarkan langkah-langkah model ADDIE (Analyze, Design, Development, Implementation, and Evaluation). ${ }^{17}$ Modul yang telah dikembangkan, selanjutnya dilakukan proses validasi modul oleh para ahli. Ahli yang terlibat yaitu ahli materi, ahli bahasa, dan ahli media. Hasil uji kelayakan modul yang diperoleh dari validasi ahli materi yaitu 97,36\%. Hasil uji kelayakan modul yang diperoleh dari validasi ahli bahasa yaitu 91,66\%. Adapun, hasil uji kelayakan modul yang diperoleh dari validasi ahli media yaitu 95,58\%. Respon peserta didik terhadap modul mendapatkan persentase 99\%. Adapun, hasil penilaian oleh guru terhadap modul mendapatkan persentase 95\%. Berdasarkan hasil uji kelayakan oleh para ahli serta respon peserta didik dan guru, maka modul ini layak digunakan dalam proses pembelajaran.

${ }^{17}$ Sukiman, Pengembangan Media Pembelajaran, Yogyakarta: PT. Pustaka Insan Madani, 2012 


\section{DAFTAR PUSTAKA}

Arlyanti, Kosasih, \& Apriliya, Pemilihan Bahan Ajar Cerita Anak Berdasarkan Karakteristik Siswa SD, Pedadikta: Jurnal Ilmiah Pendidikan Guru Sekolah Dasar, No. 1 Vol. 5 Th. 2018, h. 221-231.

Daryanto, Pembelajaran Tematik, Terpadu, Terintegrasi (Kurikulum 2013), Yogyakarta: Gava Media, 2014.

Dimyati \& Mudjiono, Belajar dan Pembelajaran, Jakarta: Rineka Cipta, 2015.

Dolong, H, Teknis Analisis dalam Komponen Pembelajaran, UIN Syarif Hidayatullah, Jakarta, No. 2 Vol. 5, Th. 2016, h. 293-300.

Ernalis, Syahruddin \& Abidin, Pengembangan Model Bahan Ajar Bahasa Indonesia Berbasis Model Pembelajaran yang Berorientasi pada Pendidikan Karakter, Jurnal Pendidikan Dasar, No. 1 Vol. 5, Th. 2016, h. 1-10.

Estuwardani \& Ali, Pengembangan Bahan Ajar Modul Tematik-Integratif dalam Peningkatan Karakter Peserta Didik Kelas 1 Sekolah Dasar, Jurnal Pendidikan Karakter, No. 2 Vol. 5, Th. 2015, h. 157-172.

Faishol, R, Pengembangan Paket Pembelajaran Ilmu Pengetahuan Sosial (IPS) Kelas IV Menggunakan Model Dick, Carey \& Carey di SD Negeri 2 Tamanagung, Jurnal Tarbiyatuna, No. 2 Vol. 2, Th. 2018, h. 31-49.

Halimah, L, Keterampilan Mengajar sebagai Inspirasi untuk Menjadi Guru yang Excellent di Abad Ke-21, Bandung: Refika Aditama, 2017.

Jampel, Tegeh \& Pudjawan, Model Penelitian Pengembangan, Yogyakarta: Graha Ilmu, 2014.

Marhayani, D, Pembentukan Karakter melalui Pembelajaran IPS, Jurnal Edunomic, No. 2 Vol. 5, Th. 2017, h. 67-75.

Madona \& Yulfia, Pengembangan IPS Berbasis Multimedia Interaktif untuk Siswa SD Kelas IV Sekolah Dasar, Jurnal Pelangi, No. 2 Vol. 8, Th. 2016, h. 221-228.

Permendikbud No. 37 Tahun 2018 tentang Perubahan atas Peraturan Menteri Pendidikan dan Kebudayan No. 24 Tahun 2016 tentang Kompetensi Inti dan Kompetensi Dasar Pelajaran pada Kurikulum 2013 pada Pendidikan Dasar dan Pendidikan Menengah.

Purwono, Urip, Standar Penilaian Bahan Ajar, Jakarta: BSNP, 2008.

Richey, R.C \& Klein, J.D, Design and Development Research Methodes, Strategies, and Issues. Mahwah, New Jersey: Lawrence Erlbaum Associattes, inc, 2007. 
Rusman, Belajar dan Pembelajaran Berorientasi Standar Proses Pendidikan, Jakarta: Prenadamedia group, 2018.

Rustini, T, Pendidikan Karakter Anak Usia Dini, Jurnal Pendidikan Anak Usia Dini, No. 1 Vol. 3. Th. 2012.

Septianti \& Rara, Pentingnya Memahami Karakteristik Siswa Sekolah Dasar di SDN Cikokol 2, Jurnal Pendidikan Islam Anak Usia Dini, No. 1 Vol. 2, Th. 2020, h. 7-17.

Stewig, J.W, Children's Preference in Picture Book Illustration, Education Leadership Journal, No. 2 Vol 3, Th. 2013, h. 273-279.

Sukiman, Pengembangan Media Pembelajaran, Yogyakarta: PT. Pustaka Insan Madani, 2012.

Susilawati, dkk, Pentingnya Pengembangan Bahan Ajar Tematik Dalam Meningkatkan Karakter Peduli Lingkungan Siswa. Jurnal Pendidikan Dasar, No. 1 Vol. 12, Th. 2020, h. 62-68.

Undang-Undang No. 20 Tahun 2003 tentang Sistem Pendidikan Nasional.

Wahyuningtyas, Penggunaan Modul Pembelajaran Penjumlahan dan Pengurangan Bilangan Bulat dengan Pendekatan CTL (Contextual Teaching and Learning) Untuk Meningkatkan Pemahaman Konsep Siswa Kelas IV Sekolah Dasar, Jurnal Pendidikan, No. 1 Vol. 2, Th. 2017, h. 8-9.

Wati, dkk, Analisis Kebutuhan Terhadap Bahan Ajar Game Based Learning Terintegrasi Karakter Kreatif. Jurnal Pendidikan Karakter, No. 2 Vol. 10, Th. 2020, h. 182-183. 
